\title{
KNOWING THAT ONE KNOWS
}

\section{Robert Segal}

Many contemporary philosophers advocate the thesis that knowing implies knowing that one knows (KK thesis). In particular, this thesis is explicitly argued for by Risto Hilpinen. In this essay, I shall (1) briefly spell out the gist of the KK thesis as presented by Hilpinen, (2) review two intuitive responses to the $\mathrm{KK}$ thesis made by David Rynin, and note how Hilpinen handles these responses, (3) lend some support for the intuitiveness (prima facie plausibility) of Rynin's remarks, and (4) present an argument against the $\mathrm{kK}$ thesis here considered, and in so doing offer a counter-example to the KK thesis.

Hilpinen considers a KK thesis which presupposes (is founded upon) a "classical" definition of knowledge, i.e., a justified true belief (JTB) account of knowledge. s knows that $\mathrm{p}$ if and only if

(i) $\mathrm{p}$ is true,

(ii) $s$ believes that $p$, and

(iii) $\mathrm{S}$ is completely justified in believing $\mathrm{p}$.

Various alternative locutions may be substituted in formulating this account of knowledge. For example, (ii) may be replaced by $\left(i i_{1}\right)$ s accepts $p$, or ( $\left.i i_{2}\right)$ s is sure of p. (iii) may be replaced by (iii) s has adequate evidence for $p$, or ( $i i_{j}$ ) $s$ has the rfght to be sure that $\mathrm{p}$, or ( $\mathrm{iii_{3 }}$ ) $\mathrm{s}$ can give adequate evidence for $\mathrm{p}$. undoubtedly, ${ }^{3}$ these various alternative locutions differ in some rather salient respects. But Hilpinen is not too conferned about distinguishing these respects, nor shall I be. Instead, let us state the classical definition of knowledge with which Hilpinen works: "If 'a believes that $p^{\prime}$ (or 'a accepts $p$ ') is expressed by 'Bap' and the justification requirement of the classical definition by 'Eap,' the definition of knowledge (Hilpinen, p. 111) may be expressed in short as: a knows that $p$ (Kap) if and only if
(i) Bap,
(ii) Eap, and
(iii) $p$ is true. 
Now, the KK thesis maintains the following: Kap Kakap, i.e., if someone ' $a$ ' knows that $p$, then 'a' knows that he ('al) knows that $p$. To break this down into simplified form, KaKap = Ka (Bap \& Eap \& p). Along with Hilpinen, I shall allow the operator ' $\mathrm{K}$ ' to distribute over conjunctions. So,

(1) KaKap $=$ (KaBap \& KaEap \& Kap). Further simplifications yield the following:

(2) KaKap $=$ (BaBap \& EaBap \& Bap \& BaEap \& EaEap \& Eap \& Bap \& Eap \& p). In short and simplified form the $K K$ thesis holds the following:

(3) (Bap \& Eap \& p) $\rightarrow$ (BaBap \& EaBap \& BaEap \& EaEap). Along with Hilpinen, I shall agree that ( 3 ) is not valid unless the consequent is implied by (Bap \& Eap). So, the validity of (3) depends on the validity of

(4) (Bap \& Eap) $\rightarrow$ (BaBap \& EaBap \& BaEap \& EaEap).

requires

Now Hilpinen correctly notes that the KK thesis

(A) Bap $\rightarrow$ BaBap, and

(B) Bap \& Eap $\longrightarrow$ BaEap.

Hilpinen accepts (A) tentatively (Hilpinen, p. 113). But he argues that (B) is definitely unacceptable (Hilpinen, p. 114). Someone might believe that $p$ and have adequate evidence that $p$, but nonetheless "fail to recognize" his evidence for what it is worth" (Hilpinen, p. 113). Given the classical JTB account of knowledge, Hilpinen concludes that one may know that $p$, but fail to know that one knows that p (in failing to recognize the adequacy of one's evidence). Because the antecedent of (B) may be true, while the consequent false, the KK thesis fails. It is clear, furthermore, that Hilpinen thinks that all the other requirements necessary to defend the $\mathrm{KK}$ thesis obtain. That is, apart from (B) not obtaining, all the other necessary conditions for the KK thesis obtain.

In order to remedy this defect in the kK thesis considered above, Hilpinen adds to the definitions of knowlegdge a fourth condition: (iv) BaEap (Hilpinen, p. 117). So, with this fourth condition added to the definition of knowledge, a new KK theiss ( $K_{1}$ ) allegedly obtains. For the only defect with the $\mathrm{KK}$ thesis was (allegedly) the falsity of (B). Since the consequent of (B) has been added as a necessary condition of knowlęgre, the defect of the $\mathrm{KK}$ thesis is removed by definition.

Hence, it is alleged that if Kap, then KaKap. It is also alleged that the truth conditions for Kap are identical with the truth conditions for KaKap. It is also 
alleged that one cannot know that $\mathrm{p}$ without knowing that one knows that $p$.

In what follows, I will argue that the KK thesis is false because (A) is false. I will argue that $\left(K K_{1}\right)$ is false as well due to the falsity of (A). But before I present my argument, let us consider some intuitive responses to the $\mathrm{KK}_{1}$ thesis.

\section{I}

As Hilpinen notes, David Rynin offers two intuitive objections to the kK, thesis. First, Rynin writes: "if one assumes that if one knows that $p$ then one must know that one knows that $p$, and if it be granted that one could be mistaken unless one knows that one knows, it would seem to me that there could be no knowledge, for in my view one could always be mistaken, i.e., one could never be sure in the intended sense." second, "if it is demonstrable that if one knows that $p$, then it follows that one knows that he knows that $p$ it would seem to me very difficult if not impossible ever to know, for it seems clear to me that this infinite process soon takes us beyond comprehension" (Rynin, p. 29).

Hilpinen is able to deal wi.th these two objections handily. Concerning the first objection, Hilpinen notes that according to the $\mathrm{KK}$ thesis, the truth conditions for Kap and KaKap are identical. Thus, if one is unsure of KaKap, then one is likewise unsure of Kap. In regard to the second objection, Hilpinen notes that since Kap and KaKap share identical truth conditions (and allegedly imply each other), "the latter statement (Kakap) yields no information in excess of that provided by the former (Kap) -. . Kap, and say, Kakakakap are just two ways of expressing the same thing in writing . . . . The difficulty here is on the side of those philosophers rejecting the $K K$ thesis, for they have the task of inventing for the tatter expression (KaKaKaKap) a meaning which differs from that of the former (Kap)" (Hilpinen, p. 126). For llilpinen, there is obviously no vicious regress to which Ryuin's objections allude.

Reflecling on how Hilpinen deals with Rynin's objections, I think the meaning of the $K K$, thesis has been made a bit more perspicuous. For it is now clear that the $\mathrm{KK}_{1}$ thesis maintains the following:

(a) 'Kap' and "KaKaKaKap' have identical truth conditions.

(b) 'Kap' and 'KaKaKaKap' mean the very same thing, i.e., the latter expression is just another way of say.ing the former (though the former is more preferable for practical reasons\}. 
I think that (b) is linguistically counter-intuitive. And this, I believe, prompted Rynin's objections to the $\mathrm{KK}$ thesis. I now want to lend some support for the prima facie plausibility of Rynin's remarks (this boils down to showing why someone might reject (b), or more likely, unreflectively assume that the negation of (b) is the case).

Why might someone intuitively assume that the negation of (b) is the case? Why would this be the natural thing to hold?

First, it is generally true that there is no inconsistency between someone ' $a$ ' not knowing that $p$, and $p$ nonetheless being the case. For example, my brother David, who resides in Connecticut, does not know that the capital of Illinois is Springfield. But it is true that the capital of Illinois is springfield. There is no inconsistency in the state of affairs where (1) David does not know that the capital of Illinois is springfield, and (2) the capital of Illinois is springfield.

Nor is there an inconsistency in David not knowing something about himself. Consider the following case. David is the great great grandchild of his great great grandfather Isaac, and David does not know that this is so. Surely there is not inconsistency here. Many people don't know who their ancestors were, although these ancestors are nonetheless these particular ancestors (with such and such offspring who had such and such offspring). clearly then, many facts are facts regardless of somebody knowing that they (the facts) are so.

But isn't "John knows that $p$ " a fact? Why then should this fact ("John knows that p") be different from other facts? Why must John know that he knows that p? Is "knowing" peculiar in the sense that whenever someone knows that $p$, he must also know that he knows that $p$ ? This is what the $\mathrm{KK}_{1}$ thesis comes to. The $\mathrm{KK}_{1}$ thesis points to an oddity ${ }^{1}$ in the logic of knowing.

Perhaps the oddity is not restricted to the concept of knowledge. Perhaps, for example, other mental concepts share this alleged feature of knowledge. Consider the verb "to want." Might someone want $p$ without knowing that (s)he wants p? Surely this is possible. David may want something without recognizing that he does. His want may be unconscious, as it were. But this alone may not suffice to show that David doesn't know that he wants $p$. However, David may want $p$, without even believing that he wants p. Perhaps David comes from a strict Jewish family. He may want to marry a non-Jewish woman (due to unusual psychological factors), but not believe that he wants to 
marry a non-Jewish woman. In such a case, David wants $p$ but does not believe that he wants $p$. Indeed, David may very well believe that he wants to marry a Jewish woman. If belief is a necessary condition of knowing, then David does not know that he wants to marry a non-Jewish woman, though he still may want to marry a non-Jewish woman. As will be shown later, someone may believe that $p$, but not believe that he believes that $\mathrm{p}$.' So, someone may believe that $p$ without knowing that (s)he believes that $p$ (again providing that belief is a necessary condition of knowing).

If the $K K_{1}$ thesis is correct, then a restricted class of facts (e.g.' 'Kap') are peculiar and distinct from most other facts in that knowledge that $p$ requires that one know that one knows.

To push this point one step further, this peculiar feature of the logic of knowing does not even apply to "not knowing that p." Consider. the following statements:

(x) S does not know that the barn is yellow.

(y) $s$ does not know that he daes not know that the barn is yellow.

(z) $S$ knows that he does not know that the barn is yellow.

One might suspect, on first blush, that the truth of the $\mathrm{KK}$ thesis would render $(x)$ and $(y)$ as sharing identical truth conditions. But this is not the case. It is obvious that $(y)$ and $(z)$ yield a contradiction. But $(x)$ and ( $z$ ) are clearly compatible. ( $x)$ and $(y)$ are also compatible. Thus, $(x)$ and $(y)$ cannot have identical truth conditions. Furthermore, (x) may be the case without (y) being the case. To see this clearly, consider the following case. San doesn't know that the barn is yellow. This is so just because the barn is, as it happens, red. Now, suppose Sam knows that the barn is red. Here is a case where $(x)$ (Sam doesn't know that the barn is yellow), and (z) (Sam knows that he doesn't know that the barn is yellow), may obviously be compatible. For if sam knows that the barn is red, he may already know, or come to know, that he doesn't know that the barn is yellow.

So, if the $\mathrm{KK}$ thesis is correct, not only does 'Kap' require "KaKap,' while other facts may be so without being known, '-Kap' is assymmetrical with 'Kap' regarding this odd logical feature of 'Kap.'

These reflections are not meant to discredit the $K K_{\text {, }}$ thesis. But I hope that I have highlighted $\frac{1}{a}$ distinguishing consequence of the $\mathrm{KK}_{1}$ thesis, $i . e .$, the distinctive logical peculiarity of 'Kap." Because 'most facts may be so without being known, I think it was 
natural and intuitive for Rynin to suppose that the fact "Kap' may be so while 'KaKap' is so as well. Working under this assumption, it is easy to see how Rynin envisioned a vicious regress being initiated by the $\mathrm{KK}_{1}$ thesis.

Second, the $\mathrm{KK}$ thesis denies levels of knowledge. This is, for reasons analogous to my first point, linguistically counter-intuitive. It is far from obvious that 'Kap' means the same thing as 'KaKap.'

But perhaps the defenders of the $\mathrm{KK}_{1}$ thesis have, as they have claimed, uncovered a peculiar and interesting feature of the logic of knowing, namely, that Kap $\rightarrow$ KaKap. Let us now turn to the $\mathrm{KK}$ and $\mathrm{KK}_{1}$ theses.

\section{IV}

Given the JTB conception of knowledge, Hilpinen argues that the $\mathrm{KK}$ thesis is false (due to the falsity of (B)). But after Hilpinen amends the JTB conception of knowledge, he arrives at a new version of the KK thesis (what I've been calling the $\mathrm{KK}_{1}$ thesis).

On the KK, thesis, the JTB conception of knowledge has a fourth condition added to it: (iv) BaEap. From this new definition of knowledge, the $\mathrm{KK}_{1}$ thesis allegedly obtains.

My present purpose is twofold. First, I want to argue that the $\mathrm{KK}$ thesis (from the tri-part, unaltered JTß definition of knowledge) is false because (A) is false. $I$ will then argue that the falsity of (A) renders the revised KK thesis, i.e., the $K_{1}$ thesis, false as well.

I think that there are numerous cases, and ordinary cases at that, where someone believes that $p$, but does not believe that (s)he believes that $p$. There are at least two ways for someone to believe $p$ without believing that (s) he believes that $p$ :

(5) Someone ' $a$ ' disbelieves that (s)he believes that $p$,

(6) Someone, 'a' withholds believing that (s)he believes that $p$. Because an instance of (5) would be a powerful denial of (A), I shall employ an instance of (5) as my denial of (A).

of course, apart. from displaying a genuine instance of (5), I shall have to show that such a belief is consistent with the definitions of knowledge assumed by the $K K$ and $\mathrm{KK}_{1}$ thesis, in order to falsify the $\mathrm{KK}$ and $\mathrm{KK}_{1}$ theses. But first, let me present an instance of (5). 
Tom is a politically liberal person. Most of his friends are politically liberal as well. Tom prides himself, in fact, on being politically aware and on carefully evaluating political candidates. He votes for the candidate he considers to be the best candidate (regardless of political affiliation). Finally, Tom does not like to upset his wife, and he very much tries to avoid arguments with her.

Now, Tom's wife, Joan, is a dogmatic Republican. She always votes Republican, regardless of who the candidates are. Furthermore, she is often politically unaware. She even refuses to discuss candidates or issues. In fact, whenever someone suggests to her that a Democratic candidate is worhty of her vote, she reacts in an emotional and almost fanatical manner, violently disagreeing. She is completely close-minded on these matters.

In our case, lom believes that Joan is dogmatic and close-minded politically. His behavior clearly indicates that he has this belief. For Tom never brings up political issues with his wife any more (he did so a few times long ago, and she reacted as described above). He never tries to persuade her to vote for a non-Republican (although he does, on occasion, try to persuade other acquaintances to vote for certain individuals, sometimes Democrats). In fact, Tom doesn't even advocate political awareness as a virtue in the presence of his vife. Nor does Tom question or criticize his wife's political dogmatisin. This is because, as it happens, Tom believes that his wife is politically dogmatic (ED). Since Tom wants very much to avoid upsetting and arguing with his wife, he behaves as he does.

The twist in this case is that although Tom's behavior clearly indicates that he believes that his wife is PD, Tom does not believe that he believes this. In fact, Tom disbelieves that he believes that his wife is PD. We may suppose, in this case, that lom has deceived himself so that he does not believe that he believes that $p$, although he does believe that $p$.

Before I try to show that Tom's belief (that his wife is PD) is consistent with the definitions of knowledge given in the $\mathrm{KK}$ and $\mathrm{KK}$ theses, two important points of clarification need to be made concerning our example.

First, someone might reject our example as a denial of (A). It might be argued that Tom does not disbelieve that he believes that $p$, but rather, Tom merely holds two contradictory beliefs. That is, Tom simply believes, on the one hand, that Joan is $\mathrm{PD}$, and on the other hand believes she is not $\mathrm{PD}$. It might be held that holding 
these contradictory beliefs fully explains the case at hand, without reference to Tom disbelieving that he believes that his wife is PD. And so, our example may be discredited.

I do not think, however, that this critique succeeds. Let us grant that Tom may have two contradictory beliefs concerning his wife's dogmatism. The further question still remains: Does Tom believe that he believes that Joan is PD? The answer to this question is "NO." To see this clearly, consider the following conversation between Tom and Bill. Bili mentions to Tom that Joan's political dogmatism disturbs his (Bill's) wife, which. is why Bill hasn't invited Tom and Joan over for dinner lately. Bill is thinking all along that Tom is aware of his wife's political dogmatism. Indeed, Bill assumed this as a result of carefully observing Tom's behavior. Tom responds: "What do you mean? My wife is as open-minded as you or me!" We may well imagine that, after some tactful discussion, Bill convinces Tom that (1) Joan is PD, and (2) Tom believed all along that she was PD. In coming to believe (2), it is obvious, I think, that Tom would be learning something from Bill; he might come to believe something which he had hitherto not believed. Tom might comment, at this point, "I guess I believed she was $\mathrm{PD}$ all along, but I refused to believe that I believed it." Perhaps Tom will even conclude that he had been deceiving himself all along, in order to sustain an image of his wife he found psychologically acceptable.

The point is simply that the case described is one, I think, where Tom believes that $p$, but disbelieves that he believes that $p$. Such cases are, I think, not uncommon.

A second objection to our example might deny that Tom's behavior is ever a conclusive indicator of Tom's belief. That is, supposing that exhibited behaviour is logically distinct from belief, one might conclude that behavior is never a conclusive indicator of belief. Thus, one might contend that although Tom behaves as though he believes that his wife is PD, he nonetheless does not believe that she is PD.

It is beyond the scope of this paper to give a full scale analysis of the nature of belief. But whatever such an analysis entails, I think that a person's exhibited behavior will at least sometimes serve as a reliable indicator of what that person believes. This could certainly be so even if exhibited behavior is logically distinct from belief. I think my assumption here is very plausible. And I think our example is one where Tom's behavior is a reliable indicator of what rom believes. Commonsense supports my point quite nicely. The point is aptly put in the hackneyed though pithy cliche "actions 
speak louder than words." This phrase is particularly relevant to our example. Tom's actions indicate that he believes Joan is PD, though Tom does not believe that he believes this.

Finally, let me make two points clear concerning our second objection. First, I have neither been presupposing nor assuming any version of philosophical behaviorism. on the contrary, my position in this essay is neutral on this issue. I have minimally supposed that behavior is sometimes an indicator of a person's belief. Perhaps the belief is a disposition to behave. Perhaps the belief, in conjunction with a desire, causes the action. Perhaps the belief is simply correlated with certain behavior, without any causal interaction at all involved. I have not committed myself to any one of these, or any other view concerning the relation between behavior and belief. I have, however, assumed that persons do have beliefs, they do exhibit behavior, and sometimes behavior is a reliable indicator of certain beliefs. Second, I have argued that many beliefs are unconsciously held. We are often unaware of many beliefs we hold. But these beliefs are still full-blooded beliefs. 1 think that this position is extremely plausible. It is very unlikely that one is conscious of all the beliefs (s)he holds. At any rate, i admit that this assumption is working in our instance of (5).

To sum up, I have tried to explicate a case where someone (Tom) believes that $p$, but does not believe that he believes that $p$. The case presented is not unrealistic. on the contrary, I believed that many instances of our case, and many slight variations on the main theme of our case, occur in the day to day lives of many people.

Now, is Ton's belief (that Joan is PD) consistent with the definition of knowledge? That is, given the definition of knowledge, and given Tom's belief (in our case), might lom know that his wi.fe is PD? I shall proceed to consider whether Tom might actually know that $p$, first given the JTB conception of knowledge (as given in the KK thesis), then on the amended JTB conception of knowledge (as given in the $\mathrm{KK}_{1}$ thesis).

Before we proceed, we may note that if Tom may know that Joan is PD, given the JTB conception of knowledge and given Tom's belief in our case, then the KK thesis is false. This would obtain just because Tom would know that $p$, but not believe that he knows that $p$. Likewise, if Tom may know that Joan is PD given the amended JTB conception of knowledge, and given Tom's belief in our case, then the KK thesis would be ralse for the same reason as the KK thesis. 
The KK thesis defines knowledge as follows. Kap if and only if

(i) p is true,

(ii) a believes that $p$, and

(iii) a is completely justified in $p$.

In our case, (ii) is satisfied. Tom believes that Joan is PD. (i) is also satisfied. Joan is, as it happens, truly PD. Even though Tom does not believe that he believes that Joan is $P D$, the fact remains that she is PD. There is, so far, nothing contradictory about this state of affairs.

Given Tom's belief (he does not believe that he believes). can Tom nonetheless be completely justified in believing that his wife is PD? One might suppose, I suspect, that Tom's disbelieved belief renders it impossible for Tom to fulfill condition (iii), i.e.. renders it impossible for Tom to be completely justified in believing that his wife is PD. Unless Tom at least believes that he believes that $p$. Tom cannot be completely justified in believing that $p$.

Even though Tom disbelieves his belief that Joan is PD, I think Tom may nonetheless be completely justified in believing that his. wife is PD. Recalling the details of our example, Tom does not irrationally believe that his wife is PD. Rather, we noted that (1) Joan always votes Republican, regardless of who is running for election, (2) Joan refuses to discuss candidates or issues, (3) Joan is often politically unaware, (4) she reacts in an emotional and almost fanatical way when it is suggested to her to vote Democratic, and (5) she is completely close-minded on political matters--she always sides with Republicans. (1) through (5) seem to be a rather plausible candidate for a complete justification that Joan is PD. And if one thinks more information is required for a complete justification, it is clear that we only need to tack it onto our case. There is no problem with our position for that.

Now, Tom is aware of these reasons (1) through (5), albeit in an unconscious way. These reasons serve as his reasons for his behavior. These reasons explain his actions. It is because of (1) through (5) that Tom behaves and believes the way he does. Tom does not want to get into an argument with his wife. He does not want to upset her.

Perhaps one might object as follows: one might identify reasons with conscious reasons, where a man's conscious reasons are those he can tell us about. To equate reasons for which he believes something with reasons he can tell us about is to assume that reasons for 
which he believes something are. conscious reasons; and that assumption is a mistake. The reasons for which people believe things are rarely conscious. People often believe things for good reasons which give them kngwledge, without being able to say what those reasons are."

In our case, (1) through (5) are Tom's reasons for believing that his wife is $P D$, although these reasons are not conscious reasons. Tom's not believing that he believes that Joan is PD is irrelevant to Tom's being completely justified in believing that Joan is PD. So long as (1) through (5) completely justify Tom's belief. and function as Tom's reasons for believing that Joan is $P D$, then Tom is completely justified in believing that Joan is PD. In our case, these reasons are unconscious reasons. Furthermore, Tom disbelieves that he believes that Joan is PD, even though his belief that Joan is PD is completely justified.

If the satisfaction of (i), (ii), and (iii). ever constitute a case of knowledge, I do not see why our case should not. At any rate, Tom's belief (where he disbelieves that he believes) daes not rule out his knowing that his wife is PD (given the definition of knowledge here assumed).

Recalling our case, suppose Bill comes along, and points out to Tom that (1) Tom believes Joan is PD, (2) Joan is PD, and ( 3 ) Tom is completely justified in believing that Joan is PD. This might well be a revelation to Tom. For Tom knew all along that she was PD, he just didn't know that he knew it. Tom might say: "I guess I knew she was PD all along. I just didn't know that I knew it."

I submit that we have posed a genuine counter-example to the KK thesis. I'om knows that his wife is PD, but Tom does not know that he knows that she is PD.

To deny that $\mathrm{KK}_{1}$ thesis, we need only show that our above case is consisteht with (iv) BaEap. Given our above case, might Tom believe that his justification for believing Joan is PD is complete, and still disbelieve that he believes that Joan is PD?

As I argued before, Tom is completely justified in believing that Joan is PD. The question before us now is: Is our case consistent with Tom believing that he is completely justified in believing that Joan is PD?

We have noted that (1) beliefs may be held for unconscious reasons, and (2) beliefs may themselves be unconsciously held. I think these two tenets enable us to render our case consistent with (iv). Tom believes that 
Joan is PD. His reasons for this belief completely justify his belief, but his reasons are unconscious ones. I suggest that Tom may also believe that his reasons completely justify him and nonetheless hold this belief unconsciously. So, our case satisfies conditions (i) through (iv). Although Tom believes that he is completely justified in believing that Joan is PD, Tom is unaware of this belief. He has, perhaps, suppressed this belief for psychological reasons. And this illustrates how Tom's disbelief that he believes that Joan is PD is compatible with the satisfaction of conditions (i) through (iv). It is only when beliefs are identified with conscious beliefs that one might plausibly suppose that (iv) rules our case a non-knowledge case. So long as beliefs may be held unconsciously, as we argued they could, Tom may believe that he is completely justified in believing that Joan is PD, and concomitantly disbelieve that he believes that Joan is $\mathrm{PD}$. I think our case (concerning Tom) captures just this sort of example.

Thus, Tom may disbelieve that he believes that $P$, even though

(i) $\mathrm{p}$ is true,

(ii) Tom believes that $p$,

(iii) Tom is completely justified in believing that $p$, and (iv) Tom believes that he is completely justified in believing that $p$.

We may conclude, then, that the $\mathrm{KK}$ and $\mathrm{KK}$ theses are false. This is just because both theses requite (A) Bap $\rightarrow$ BaBap. Since the denial of (A) (at least one instance thereof) is compatible with the definition of knowledge given in both the $\mathrm{KK}$ and $\mathrm{KK}$ theses, our single example (concerning Tom) serves as a counter-example to both the $\mathrm{KK}$ and $\mathrm{KK}_{1}$ theses.

In this essay, I have tried to show that someone may believe that p, while nonetheless not believe that (s)he believes that $p$. Given what $I$ take to be an instance of this claim, namely the example concerning Tom, I have tried to show that Tom may know that his wife is politically dogmatic, but not know that he knows this (given the conceptions of knowledge assumed in the $\mathrm{KK}$ and KK theses). Our conclusion minimally shows, if it is at all correct, that the $\mathrm{KK}$ and $\mathrm{KK}$, thesis are false (given the definition of knowledge ${ }^{1}$ supposed within each respective thesis). Although the counter-example 1 have presented admittedly depends on (1) unconscious reasons, and (2) unconscious beliefs, I think that these 
assumptions axe extremely plausible. A full scale analysis of unconscious reasons and unconscious beliefs is, however, beyond the scope of this essay.

University of Illinois, Urbana 
NOTES

${ }^{1}$ Risto Hilpinen, "Knowing that one knows and the classical Definition of Knowledge," Synthese, 21 (1970), pp. 109-32.

${ }^{2}$ Some alternative formulations of this definition may render my forthcoming counter-example to the KK thesis more suspect than other formulations. This will perhaps serve to highlight certain differences in these alternative formulations.

${ }^{3}$ This added condition to the definition of knowledge is not simply ad hoc. There is a defense for it. See Hilpinen, pp. $115-17$.

${ }^{4}$ Let me re-emphasize that this addition is not simply ad hoc. I am, however, pretty suspicious about the validity of this added condition of knowledge.

${ }^{5}$ David Rynin, "Knowledge, Sensation, and certainty," in Epistemology: New Essays in the Theory of Knowledge, ed. Avrum Stroli (Harper\& Row, $\frac{1967}{19}$ ), pp. 8-32.

$6_{I}$ do not mean that (A) is the oly fault with the $\mathrm{KK}$ theses. Perhaps the KK theses has other problems too.

7 I have in mind here an unconscious withholding, i.e., the person is unaware of his belief, and has no belief, one way or the other, concerning his belief. This may be contrasted with someone consciously withholding a belief on whether or not he actually believes that $\mathrm{p}$.

${ }^{8}$ of course, it is often very difficult to determine just what someone believes from the actions of that person. But if enough background information were known (concerning the circumstances, the sincerity of the person in these circumstances, etc.), certain actions would often enable one to determine certain beliefs held by the person in question.

${ }^{9}$ Giblbert Harman, Thought (Princeton: Princeton University Press, 1973), p. 28 . I borrow this idea from Harman, who argues for this position compellingly. My own views concerning unconscious beliefs and unconscious reasons are much influenced by Harman's book Thought. 